\title{
A Constância Temporal da Criação por Neḥeḥ e Djet: uma Breve Reflexão Sobre a Construção Cultural do Tempo Para os Antigos Egípcios
}

\author{
The Time Constacy of the Creation by Neheh e Djet: a Brief Reflection \\ About the Cultural Construction of the Time for the Ancient Egyptians
}

\begin{abstract}
Giselle Marques Camara ${ }^{1}$
${ }^{1}$ Doutora em História pela Pontifícia Universidade Católica do Rio de Janeiro. Professora do Quadro Auxiliar em História Antiga da Pontifícia Universidade Católica do Rio de Janeiro. Professora e pesquisadora em História Antiga do CEHAM/NEA - UERJ. E-mail: gisellemarquescamara@yahoo.com.br.
\end{abstract}

Recebido em 29 de setembro de 2019; Aceito em 04 de abril de 2020

\section{RESUMO}

O estudo apresentado nesse artigo se debruça sobre o modo pelo qual a ideia de temporalidade no Antigo Egito pode ser compreendida por meio de sua corporificação na imagem de dois "deuses-princípios": um deles manifestado pela polaridade feminina Djet e o outro pelo seu complemento masculino Neheh. Apesar de ambos os termos serem comumente traduzidos por "duas eternidades" ou "eternidade/tempo", respectivamente, Djet parece encerrar um princípio estático, manifestando uma concepção de tempo que se confunde com espacialidade, enquanto Neḥeh expressa a ideia dinâmica dos ciclos ininterruptos da natureza. Além de buscar expor de uma maneira objetiva o universo de sentido expresso pelo par, por meio de uma literatura sobre o tema já consagrada, o breve estudo busca lançar novos questionamentos sobre a interação de tais princípios cósmicos geradores de tempo.

Palavras-chave: Egito Antigo; Religião; Temporalidade no Antigo Egito.

\section{ABSTRACT}

The study presented in this article focuses on the way in which the idea of temporality in Ancient Egypt can be understood through its embodiment in the image of two "principle gods": one manifested by the female polarity Djet and the other by its complement male Neheh. Although both terms are commonly translated as "two eternities" or "eternity/time", respectively, Djet seems to end a static principle, manifesting a conception of time that is confused with spatiality, while Neheh expresses the dynamic idea of uninterrupted cycles of nature. In addition to seeking to expose in an objective way the universe of meaning expressed by the pair, through a literature on the already established theme, the brief study seeks to raise new questions about the interaction of such time-generating cosmic principles.

Keywords: Ancient Egypt; Religion; Temporality in the Ancient Egypt. 
ISSN 1982-8713

Os "deuses" ou os "princípios" Neheh ( $n h \underline{h}$ ) e Djet (d.t.t) abundam nas mais diversas naturezas de fontes ao longo de todos os séculos em que a cultura egípcia ${ }^{58}$ antiga se manteve viva na memória dos que habitaram o território que lhe correspondia ou que de alguma outra forma dela se nutriram. Figuraram a partir dos Textos das Pirâmides e foram ressignificados até mesmo durante o Egito Copta ${ }^{59}$. Desde a inauguração da Egiptologia como área de conhecimento acadêmica, são recorrentemente alvo de muitas interpretações por parte de eruditos tanto contemporâneos como de outrora.

Muitas foram as terminologias e as concepções usadas pelos egiptólogos e filólogos em suas tentativas de apreender a natureza expressa pelas divindades genesíacas, que de certa maneira tornassem Neheh e Djet mais familiares ao nosso universo semântico: tempo pequeno/tempo grande; duas eternidades; eternidade/tempo; cíclica/linear estacionária. Revisitaremos os referidos conceitos ao longo da exposição, não somente por serem alguns dos mais debatidos na contemporaneidade, mas, outrossim, por se tratar de estudiosos que elegemos como interlocutores da presente reflexão.

Em seguida, listaremos sucintamente as mais significativas interpretações que os termos assumiram ao longo da história da Egiptologia, de modo que o leitor possa ter as referências que construíram a trajetória interpretativa das concepções em questão: para A. Gardiner (1905) o vocábulo Djet significava passado e Neheh futuro; W. Thausing (1934) defendia ser Neḥeh sinônimo de vida terrena e Djet vida post mortem; A.M. Bakir

\footnotetext{
${ }^{58} \mathrm{O}$ presente artigo consiste na discussão que integra um dos capítulos da tese intitulada: "Tempo e Maat na Antiga Kemet", defendida pelo Programa de Pós-Graduação em História Social da Cultura/Departamento de História da Pontifícia Universidade Católica do Rio de Janeiro, Rio de Janeiro, 2018.

59 Os coptas ou cristãos egípcios criaram uma tradição cultural que fez intercambiar elementos socioculturais do passado faraônico e da longa ocupação greco-romana com o Cristianismo, crença esta que começou a ganhar contornos e difusão no Egito a partir do século I a.C.
} 
NEARCD: Revista Eletrônica de Antiguidade 2020, Volume XII, Número I - ISSN 1982-8713

Núcleo de Estudas da Antiguidade -NEA

Universidade do Estada do Rio de Janeiro

ISSN 1982-8713

(1953) interpretava Neheh como eternidade antes da criação e Djet eternidade pós criação. E. Otto (1954) entendeu Neḥeḥ como a eterna repetição do mesmo e Djet como a eterna constância do invariável; Morenz (1962) vê Neḥeḥ como tempo cíclico e Djet como tempo linear; para W. Westendorf (1983) Neheh é tempo e Djet é espaço ${ }^{60}$.

De maneira geral, Neḥeḥ (nḥh) e Djet (d.t.t) são referidas, respectivamente, por "eternidade" e "tempo", ou por "duas eternidades". Isso porque, ambas as divindades carregam a qualidade da infinitude, ou seja, de ausência de delimitação cronológica enquanto a existência acontece no cosmo: "No Papiro de Chonsumes (agora em Viena), datado da 21a Dinastia, Neḥeh e Djet são acompanhados pelos 'milhões de anos' como personificação do tempo, e a expressão 'milhões de anos', ou outros termos, geralmente ocorrem em textos como sinônimo para ambas" 61 (HORNUNG, 1992, p.65).

A apresentação dos conceitos por meio do uso etimológico dos vocábulos "tempo" ou "eternidade" expressam uma tentativa forçosa de fazê-los caber em um universo de representação de mundo muito diverso do nosso, ao associar, respectivamente, a palavra "tempo" aos ciclos astronômicos (rotações, translações, lunações, equinócios) e aos ciclos da natureza (estações, cheias dos rios, gestações) e a palavra "eternidade" o seu estado oposto, ou seja, a ausência de movimento, a imutabilidade eterna. Erik Hornung, por exemplo, foi cauteloso ao optar pela generalização "eternidades", resguardando que, em absoluto, tais vocábulos expressavam a conceptualização por trás das mesmas:

A concepção egípcia de eternidade nos leva a dois termos importantes, Neheh e Djet. Embora as duas terminologias não exprimam eternidade em sentido absoluto, eles chegam o mais próximo possível de significar "eternidade" sem

\footnotetext{
${ }^{60}$ Aos leitores interessados em aprofundar o assunto, o egiptólogo Frédéric Servajean desenvolve na introdução da obra Djet et Neheh. Une histoire du temps égyptien, um debate historiográfico sobre o desenvolvimento do conceito. SERVAJEAN, Frédéric. Djet et Neheh. Une histoire du temps égyptien. Montpellier: Orientalia monspeliensia. Institut d'égyptologie François Daumas, Archéologie des sociétés méditerranéennes, Université Paul Valéry-Montpellier III, 2007.

${ }^{61}$ Texto extraído da versão em língua inglesa do original em alemão: "In the Chonsumes Papyrus (now in Vienna), which dates from Dynasty 21, neheh and djet are joined by the "million years" as personification of time, and the expression. 'millions of years' often occurs in whitten texts as a synonym for both of the others terms".
} 
ser realmente sinônimo dela, pois representam a soma de todas as unidades de tempo imagináveis ${ }^{62}$ (HORNUNG, 1992, p. 142).

Françoise Dunand e Christiane Zivie-Coche (DUNAND e ZIVIE-COCHE, 2004, p. 69). atentam para a impropriedade da tradução "eternidade", amplamente usada para suprir a ausência de vocábulos que possam oferecer uma compreensão mais satisfatória sobre tais termos. Principalmente, pelo fato das "eternidades" serem "duas", o que pressuporia concepções distintas para cada uma das terminologias. Sendo assim, podemos considerar que quaisquer tentativas de fazê-las caber em nosso universo semântico, resultaria em subtrair a possibilidade de se alcançar uma interpretação menos sugestionada. Estaremos, portanto, entendendo Neḥeḥ e Djet, como dimensões temporais que viabilizam a existência inaugurada com a criação, e empregando a terminologia "tempo" de maneira genérica, ou seja, sem qualquer comprometimento conceitual. Por conseguinte, buscaremos estabelecer as diferenças qualitativas que essas duas facetas do tempo parecem revelar no cenário cósmico do Egito Antigo, sem, contudo, deixar de considerar que os princípios assumem um significado mais pertinente em sua complementaridade e relação. Vale ressaltar que, no universo linguístico da antiga Kemet existiram outras palavras associadas à ideia de "tempo", bem como a consciência e conhecimento por parte dos egípcios de que o tempo astronômico poderia ser mensurado, e era parâmetro fundamental para conferir o ritmo dos cronogramas que uma sociedade profundamente burocratizada requeria para manter 0 pragmatismo das atividades cotidianas. Nos ocuparemos um pouco mais adiante deste tópico. Defendemos que tanto o "tempo imanente" como o "tempo transcendente" constituem facetas de uma mesma realidade existencial, inaugurada com o vir-a-ser de Atum.

Não obstante, registamos no vocabulário egípcio, um amplo léxico a respeito do Tempo: as várias partes do dia assumiam um termo específico; a expressão

\footnotetext{
62 Texto extraído da versão em língua inglesa do original em alemão: "The Egyptian concept of eternity brings us to two important terms, neheh and djet. While the two terms do not signify eternity in an absolute sense, they do come as close as possible to meaning 'eternity' without actually being synonymous with it, since they represent the sum of all conceivable units of time".
} 
h3w designaria um bloco de tempo, expressando um sentido semelhante ao de $r k$; o vocábulo ḥ $w$, que pode ser traduzido como "duração", poderia designar o tempo de uma vida ou um período de tempo genérico, contrariamente a rnp.t e tr que expressariam dimensões concretas do tempo, respectivamente, "ano" e "estação"; finalmente, a ideia e ocorrência episódica, de "vez", poderia ser transmitida pela palavra $s p$, sendo a sua negação ( $n s p$ ) tradutora de uma noção de "nunca" (PIRES, 2015, p.3).

Figura 1. Representação dos hieróglifos para as palavras Neḥeh (tradução: "tempo") e Djet (tradução: "eternidade").

Fonte: http://www.templestudy.com/2008/06/25/time-and-eternitynaegyptian-dualism/

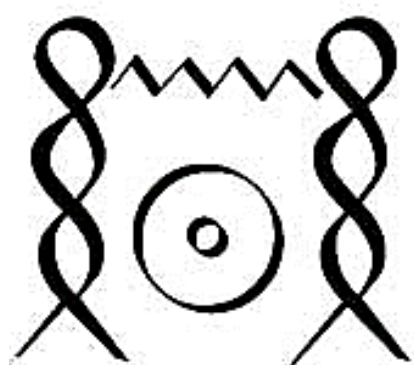

neheh (nhh) "time"

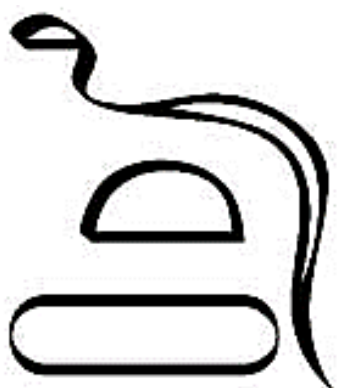

djet (dt) "eternity"

Iniciaremos a reflexão expondo como os cônjuges de uma maneira geral são compreendidos, de modo que nos sirvam de parâmetro para delinear a argumentação que se pretende sustentar. Reiteramos a importância de deixar bem claro que tais conceitos são fluidos, e qualquer tentativa de atribuir contornos epistémicos rígidos, restringe a possibilidade de explorar outras possíveis interpretações das divindades cujos princípio se complementam, visto que é na interação do par que se revela a riqueza simbólica expressa no sentido maior de tempo. O tempo é a unidade de pertença de toda a criação, e Maat o princípio que aglutina, direciona e concede coerência a tudo que nele está contido. Portanto, é considerável registrar desde já que em nenhuma fonte até hoje encontrada - não apenas as que foram tomadas como objeto de análise pelo presente estudo, como as que os egiptólogos se debruçaram a longo de mais de um século de pesquisas -, carregam a referência de Neḥeḥ e Djet fora do âmbito da criação, ou seja, no contexto do Oceano Primordial. Os trechos do Texto 
NEARCD: Revista Eletrônica de Antiguidade 2020, Volume XII, Número I - ISSN 19882-8713

Núcleo de Estudas da Antiguidade -NEA

Universidade do Estado do Rio de Janeiro

ISSN 1982-8713

dos Sarcófagos 78 e 80 situam o aparecimento de ambas como protagonistas das primeiras cenas da gênesis segundo a mítica heliopolitana. Essas referências serão retomadas.

\section{Textos dos Sarcófagos 78 (CT 78)}

Eu sou o ba de Shu, a quem foi dado Nut acima e Geb sob os pés. Estou entre eles [Geb e Nut].

(...) Eu sou a Eterna Repetição [Neheh]], pai de um número infinito. Minha irmã é Tefnut, filha de Atum, que erqueu a Eneade. (...)

Eu sou aquele que suportou milhões repetidos para Atum: que é a Eterna Uniformidade [Djet], minha irmã Tefnut.

\section{Textos dos Sarcófagos 80 (CT 80)}

Ei, vocês, "Oito Infinitos [Heḥu]" - um número infinito de Infinitos [Heḥu], que circundam o céu com os seus braços, que delineiam o céu e o horizonte de Geb! Shu deu-lhes o nascimento, fora da Inundação [hḥw], fora das Águas [nw], fora da Escuridão [kkw], fora do Caos [tnmw]. para que ele pudesse separar Geb e Nut, sendo Shu a Eterna Repetição [Eterna repetição do mesmo] [Neḥeh], e Tefnut a Eterna Uniformidade [Eterna constancia do invariável] [Djet] Eu sou o ba de Shu, que está no Grande Inundação, que ascende ao céu como ele deseja, que desce a Terra quando seu coração determina.

Eu sou a Existência, o Senhor dos Anos, a Existência na Eterna Repetição [Eterna repetição do mesmo] [Neḥeh], o Senhor da Eterna Uniformidade [Eterna constancia do invariável] [Djet] - o mais velho que Atum fez com sua eficácia, quando ele deu à luz a Shu e a Tefnut em Heliopolis, quando ele era um e se tornou tRás, quando Geb foi separado de Nut, antes do nascimento do primeiro Corpo, 
NEARCD: Revista Eletrônica de Antiguidade 2020, Volume XII, Número I - ISSN 19882-8713

Núcleo de Estudas da Antiguidade -NEA

Universidade do Estada do Rio de Janeiro

ISSN 1982-8713

antes que as duas Enéades originais se desenvolvessem e existissem comigo $^{63}$.

Figura 2. Esquema da tríade Atum/Neheh/Djet. Fonte: o autor

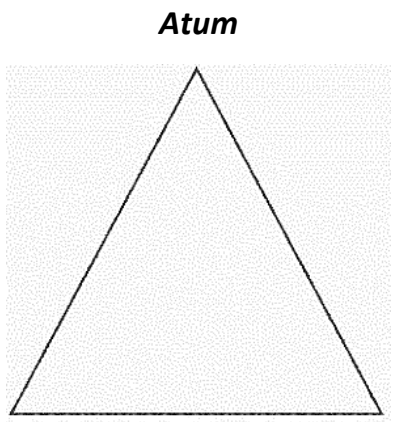

Shu - Existência

Neheh
Tefnut - Maat (ordenação)

Djet

Neheh, a polaridade masculina, identificada ao deus Shu, comumente é compreendida como a sucessão de ciclos repetidos ininterruptamente: o dia / a noite; ao longo de cada dia, o sol nascente / o sol a pino / o sol poente; a sucessão dos ciclos anuais dos festivais divinos nos templos; as cheias do rio Nilo; as estações do ano; os ciclos de aparecimento e desaparecimento de constelações no céu egípcio / os equinócios. Ou seja, Neḥeh, gera e/ou é o resultado do movimento dos corpos celestes, portanto determinado pelo deus solar Rá. Era também representado pelo escaravelho,

\footnotetext{
${ }^{63}$ Trecho extraído do CT - 78 e 80, traduzido do original em hieróglifos para a língua inglesa por: BUCK, Adriaan de apud ALLEN, 1998, p. 23.

"I am the ba of Shu, / to whom was given Nut atop him and Geb under his feet. / I am between them. / (...) I am Eternal Recurrence, father of an infinite number. / My sister is Tefnut, daughter of Atum, who bore the Ennead. / (...) I am the one who bore repeated millions for Atum: / that is Eternal Sameness, / hat is my sister Tefnut. (...) O you 8 Infinites Ones - an infinite number of Infinite Ones / who encircle the sky with your arms, / who draw together the sky and horizon of Geb! / Shu has given you birth out of the Flood, / out of the Waters, out of Chaos, out of the Darkness, / that he might allot you to Geb and Nut, /while Shu is Eternal Recurrence and Tefnut is Eternal Sameness. / I am the ba of Shu who is at the Great Flood, / who goes up to the sky as he wishes, / who goes down to the earth as his heart decides. (...) I am Life, lord of years, / Life of Eternal Recurrence, / lord of Eternal Sameness - the eldest that Atum made with his efficacy, / when he gave birth to Shu and Tefnut in Heliopolis, when he was one and developed into three, / when the parted Geb from Nut, / before the first Corps was born, / before the two original Enneads developed and were existing with me".
} 
NEARCD: Revista Eletrônica de Antiguidade 2020, Volume XII, Número I - ISSN 19882-8713

Núcleo de Estudas da Antiguidade -NEA

Universidade do Estada do Rio de Janeiro

ISSN 1982-8713

associado ao deus Kheprer, o sol do meio dia (cada forma solar está associada a uma entidade diferente de $R a ́)^{64}$, portanto ao movimento do "vir a ser". Um estado dinâmico de existência, impregnado de potencialidade, já que intermedeia a ação da passagem da não existência para a existência.

Portanto, o tempo Neḥeh, é associado ao princípio dinâmico h̆pr, que engendra a dimensão do "vir a ser", expressando a ação criativa em seu estado de pleno movimento. Não é a ausência da existência, nem a existência consolidada. É a existência em trânsito, a qual podemos atribuir, segundo Assmann (ASSMANN, 1998, p. 18), a adjetivação de "reversibilidade", distinta da outra construção de tempo Djet, associada a Osíris. Essa última é ainda mais distante da nossa percepção moderna e ocidental de tempo, por ser definida, segundo os egípcios, como a dimensão da absoluta imutabilidade. Qualificada por Assmann pelos epítetos de "estabilidade" e "permanência", seus símbolos eram a múmia e a pedra. Djet é a polaridade feminina identificada com a deusa Tefnut, princípio estático, que só assume completude e sentido se associada a seu cônjuge.

Assmann afirma: “ (...) Djet não é um conceito linear de tempo, mas sim a suspensão do tempo" 65 (ASSMANN, 1998, p. 18). Apropriando-se da frase como base de reflexão, poderíamos dizer que $D j e t$ estaria em uma posição diametralmente oposta a construção de um tempo linear e causal, se entendermos o "tempo" referido na frase acima desta maneira. Em decorrência de tal percepção, alguns egiptólogos a compreendem como um princípio mais vinculado à ideia de "espaço", o local de "aparecimento/surgimento" dos entes no cosmo, do que de "tempo" entendido segundo nossos parâmetros culturais, ou seja, visto como a sucessões de ciclos

\footnotetext{
${ }^{64} \mathrm{O}$ deus criador poderia ser designado por quatro termos distintos, cada um associado a uma divindade de acordo com a posição do astro em seu percurso diário: Rá, o mais usual, referia-se à plenitude zenital do sol (representada por um homem com um disco solar na cabeça), Atum era a sua manifestação vespertina, Kheprer, o sol da manhã, e Aton o nome do disco luminoso que percorria o céu. (CARDOSO, 1999, p. 59).

${ }^{65}$ Texto extraído da versão em língua inglesa do original em inglês: "Hence Djet is not a linear concept of time, but rather the suspension of time".
} 
cronológicos (tal como mensurado astronomicamente) ou como a dimensão onde se desenrola toda a história humana. Não é incomum a palavra Djet na língua egípcia antiga vir acompanhada do determinativo associado à categoria de espaço:

A múmia identificada a Osíris, em que um de seus atributo - Unnefer - expressa "aquele que permanece na perfeição", revela a imutabilidade da natureza daqueles que são "eternos em Osíris", ou seja, os mortos. Se compreendermos o universo egípcio a partir da óptica que estamos buscando imprimir, ou seja, não dicotomizando "transcendência" de "imanência" - visto que a existência, tal como defendemos, é a totalidade de "tempos" e "espaços" sobrepostos-, essa simbologia é exemplar: a morte, nesse sentido, pode tanto ser um símbolo de degeneração para que um novo ciclo seja iniciado - papel de Seth na criação - mas também, a noção de que a existência está assentada em uma dimensão de totalidade onde esses ciclos encontram sustentação para a sua continuidade. A múmia é encerrada em um ataúde cuja tampa representa Nut, e Geb está metaforizado na composição inferior que acolhe o corpo. A morte, portanto, representa o retorno ao estado anterior a separação entre Geb e Nut por Shu, o que gera a condição para que os ciclos de eternas repetições - Neḥeh - ocorressem. Se Shu não cria a espacialidade para que a dimensão do tempo a ele relacionada (Neḥeh) possa atuar gerando os ciclos cósmico, a "múmia/Osíris" existe apenas no domínio da deusa Tefnut, que é Djet. Ambos os princípios Shu/Neheh e Tefnut/ Djet, sustentam de fato a criação, como temos buscado demonstrar, e qualquer tentativa de compreensão em relação ao sentido de tempo engendrados pelo par de princípios a ele referidos, deve estar assentada na análise dos mitos de criação, que descrevem a geração das forças cósmicas Shu/Tefnut a partir das quais toda a existência foi viabilizada.

Erik Hornung contra-argumenta as teses que atribuem apenas à Djet o sentido de espacialidade:

Neḥeh e Djet têm conotações espaciais também. A "Câmara Subterrânea" da vida após a morte é inteiramente preenchida pelo tempo, e o falecido se pergunta ao longo de caminhos estendidos tanto pelo espaço quanto pelo tempo. De acordo com uma imagética bem documentada, Neheh e Djet atuam como pilares de apoio para a abóbada celeste, e a existência contínua 
NEARCD: Revista Eletrônica de Antiguidade 2020, Volume XII, Número I - ISSN 19882-8713

Núcleo de Estudas da Antiguidade -NEA

Universidade do Estada do Rio de Janeiro

ISSN 1982-8713

do mundo depende deles. Nos Textos dos Sarcófagos estas funções levam à identificação de Neheh e Djet com o deus Shu, que dividiu o céu e a terra no momento da criação, e com sua irmã Tefnut. O Livro da Vaca Celeste do Período de Amarna os representam como pilares vivos que sustentam os céus; eles aparecem pela primeira vez aqui como um casal divino e, assim, ajudam a criar uma imagem visual convincente da unidade indivisível do tempo e espaço que surgiu no momento da criação ${ }^{66}$.

A tumba egípcia era denominada ḥw.t-neḥeh; pr-d.t, as "moradas da eternidade". Já a pedra se associava também ao eterno devido a sua grande durabilidade. Foi o material usado para esculpir templos e tumbas, por isso é que nos testemunham o passado por meio de resquícios que rasgaram o tempo chegando até nós. As demais construções - casas, palácios - por serem feitas de tijolo de adobe, esvaneceram-se. Assim, voltamos a uma compreensão da lógica mítica versus a lógica histórica: no mito os fatos, a materialidade dos acontecimentos, é irrelevante - não importa se o "personagem humano" se chama Hori ou Unefer, pois no Duat, todos se tornam Osíris. O mundo egípcio é o espelho e a encenação viva de uma trama desenrolada a partir da criação. Portanto, é sempre bom reafirmar que, a partir desse prisma, o tempo é a TOTALIDADE da existência. Não há "eternidade divina" e "tempo humano", ou qualquer outra natureza de dicotomização que possa estabelecer uma distinção entre a esfera imanente e transcendente. A ordem da criação - Maat perpassa todos os entes, por isso, ela se faz tanto presente no âmbito tanto daqueles que pertencem ao domínio de Rá/Hórus - regidos por Neheḥ-, que é o "humano", como

\footnotetext{
${ }^{66}$ Texto extraído da versão em língua inglesa do original em alemão: "Neheh e Djet have spatial connotations as well. The "hidden room" of the afterlife is entirely filled by time, and the deceased wonder along paths that extend through space and time alike. According to a well-documented image, Neheh e Djet act as supporting pillars for the arc of heaven, and the continued existence of the world depends on them. In the Coffin Texts this functions leads to the identification of Neheh e Djet with the god Shu, who divided heaven and earth at the time of the creation, and his sister Tefnut. The Book of the Celestian Cow from the Amarna Period depicts them as living pillars supporting the heavens; they appear for the first time here as a divine couple, and thereby help create a compelling visual image of the indivisible unity of the time and space and space that came into being at the time of creating". HORNUNG, Erik. Idea into Image. Essays on Ancient Egyptian Thought, p.69.
} 
NEARCD: Revista Eletrônica de Antiguidade 2020, Volume XII, Número I - ISSN 19882-8713

Núcleo de Estudas da Antiguidade -NEA

Universidade do Estada do Rio de Janeiro

ISSN 1982-8713

ao domínio do reino de Osíris - regidos por Djet -, ou seja, no Duat. Além disso, é também valioso problematizar a ideia de finitude e infinitude.

No nosso mundo conformado pelas delimitações temporais passado, presente e futuro, ainda que consigamos visualizar um futuro em aberto, até mesmo infinito, a falta do estabelecimento de uma causa primeira para o desenrolar de uma ação qualquer, nos parece impensável, e sempre nos faz referir a máxima: “Quem nasceu primeiro, o ovo ou a galinha?". Portanto, conformar Neheh e Djet nesses conceitos, também parece ser inapropriado. As concepções de finito e infinito se estabelecem a partir de uma perspectiva particular de tempo, que é a nossa. Ainda que, a física quântica aponte para "leis", muitas ainda empiricamente a serem provadas, que estariam por trás das dinâmicas celestes, revelando outras perspectivas sobre o entendimento espaço/tempo, nossa compreensão está demasiado tecida em um "mundo de sentido", em grande parte cultural, que dificilmente alcança algo que está para além dela. Tratando do tempo no Egito, as qualificações finitude e/ou infinitude parecem não fazer sentido, em um universo onde tudo apenas é. Até mesmo a criação, como foi discutida na seção anterior, não pode ser situada no início de um processo genesíaco, pois ela acontece a todo o momento e simultaneamente em vários níveis cósmicos: no nascimento de um ser na natureza, no primeiro dia de cheias do rio Nilo, no nascer do sol diariamente, na revolução dos astros no céu, no encontro da alma "Osíris" no Duat com o deus solar. A criação é um ato simultâneo e ininterrupto. Não devemos olvidar, outrossim, que os egípcios ainda acreditavam em um cenário anterior a criação, do qual Atum, era apenas um dos protagonistas, e no qual não há nenhuma referência de tempo que possa ser estabelecida. A cosmovisão kemetiana era demasiadamente complexa e profundamente distinta do mundo tal como hoje o experimentamos.

Com os conceitos Neheh e Djet chegamos nos limites do tempo e também na questão de uma eternidade estar além de todos os tempos. A morte para os egípcios não significava um passo fora do tempo para a eternidade. $O$ falecido permaneceu dentro do tempo; como já observado, eles experimentaram novas vidas no submundo e, assim, participaram da órbita diária do sol, uma ligação temporal e espacial entre essa vida e o futuro. E, no entanto, ao entrar na vida após a morte, eles também gozavam de uma existência divina em que 
NEARCD: Revista Eletrônica de Antiguidade 2020, Volume XII, Número I - ISSN 1982-8713

Núcleo de Estudas da Antiguidade -NEA

Universidade do Estada do Rio de Janeiro

ISSN 1982-8713

se aplicavam diferentes padrões ou diretrizes temporais. A partir desta perspectiva divina, era possível uma visão geral do tempo que se estendia em muitas direções; essa visão geral abrangeu o passado e o futuro ${ }^{67}$.

E assim, por inúmeros registros, atestamos Neheh e Djet na esfera da vida terrena e na esfera da vida post mortem: "Ensinamentos do governador da capital, vizir Ptah-Hotep, sob a majestade do rei do Alto e Baixo Egito, Isési, que viva por Djet e por Nehẹ ${ }^{68}$. Nos Textos dos Pirâmides, prenuncia-se: “A vida do rei é Nehẹh / seu limite é Djet $^{69 \prime \prime}$. A partir de nossa perspectiva, as interpretações do egiptólogo português José das Candeias Sales em relação aos conceitos de tempo bem como a fragmentação de Assmann em "tempo grande" e "tempo pequeno" não encontram sustentação, nem sequer se suas interpretações estivessem baseadas apenas em uma inserção metodológica. Sales ${ }^{70}$, secciona o tempo egípcio em três subgrupos: a concepção cíclica (Neheh) que abarcaria todos os ciclos do universo e os ritos/festivais a eles relacionados; a concepção linear (Djet) entendida como o instante da criação no exato momento de vir a ser (sep tep) de Atum, bem como a duração da existência e experiência humana terrena (nascimento, crescimento, envelhecimento e morte); e a concepção imóvel ou estacionária que seria do mundo dos mortos, onde os ciclos não mais atuariam, e o cenário se equipararia a um eterno presente.

\footnotetext{
${ }^{67}$ Texto extraído da versão em língua inglesa do original em alemão: With the concepts neheh and djet we arrive at the limits of time and also at the question of an eternity be beyond all time. For the Egyptians death did not mean a step out of time into eternity. The deceased remained within time; as noted already, they experienced new lifetimes in the underworld and thereby participated in the daily orbit of the sun, a temporal and spatial link between this life and the hereafter. And yet by entering into the afterlife they also enjoyed a divine existence in which different temporal standards or guidelines applied. From this divine perspective, an overview of time extending in many directions was possible; such an overview encompassed the past as well the future. ". Idem, ibidem, p.69.
}

${ }^{68}$ ARAÚJO, Emanuel. ARAÚJO, Emanuel. Escrito para a eternidade - literatura no Egito faraônico. Brasília: UNB, 2000, p. 245.

${ }^{69}$ Texto extraído da tradução original na língua egípcia antiga para a língua inglesa: : “The King's lifetime is Neheh /His limit is Neheh e Djet". Utterance 1442: FAULKNER, Raymond O.. The Ancient Egyptian Pyramid Texts. Oxford: Oxford University Press, 1969.

70 SALES, José das Candeias. "Concepção e Percepção de Tempo e de Temporalidade no Egipto Antigo". In: Política(s) e Cultura(s) no Antigo Egipto. Lisboa, Chiado Editora, 2015. 
Assmann secciona o tempo egípcio em "tempo pequeno" e "tempo grande": o tempo da perecividade humana, onde os acontecimentos se desenrolam na simplória trajetória cotidiana, e o tempo que se apresenta na dimensão diametralmente oposta ao tempo da criação, esfera dos deuses e da eternidade post mortem. No livro The search of the god in Ancient Egypt ${ }^{71}$, o egiptólogo estabelece uma divisão entre três esferas do tempo em que a enéade heliopolitana estaria comportada: Atum "preexistência", Shu/Tefnut, Ísis/Osíris e Seth/Nefitís - tempos primaveris e Hórus tempo histórico. Ainda que saibamos que Assmann não está se referindo ao "tempo histórico" tal como o entendemos a partir da Modernidade, existe uma dicotomização em relação as instâncias de vivência do tempo que está em consonância com a ideia de "tempo pequeno e tempo grande". Voltaremos a reiterar que, não partilhamos dessa concepção no presente trabalho, pois, não compreendemos o tempo a partir de uma perspectiva linear, onde a gênesis teria supostamente se dado na direção da criação humana, apartando-o do tempo maior regido pelos grandes princípios cósmicos. Se não há linearidade nem um telos histórico, consequentemente os egípcios periodizavam o seu cotidiano de uma outra forma. O fato de acreditarem em um tempo cíclico e eterno não subtraía a necessidade da construção de marcos referencias temporais que dessem conta do pragmatismo exigido pelas atividades diárias: cronogramas de obras, datas festivas, anos de reinado de um faraó, ciclos de movimentos celestes, periodicidade das cheias do Nilo etc.

Os egípcios, desde o princípio do terceiro milênio, construíram conhecimentos nos campos da astronomia e da matemática, que os permitiram compreender que o movimento de translação da terra em torno do sol poderia ser desmembrado em 365 dias, com cada dia composto de 24 horas. Esses 365 dias foram divididos em 12 meses de 30 dias, e em "três estações" (akhet, peret, shemu) ${ }^{72}$. Os cinco dias que finalizavam

\footnotetext{
${ }^{71}$ ASSMANN, Jan. Search for a God in Ancient Egypt. Nova York: Cornell University Press (Ithaca \& London), 2001, pp. 121-123.

${ }^{72}$ Akhet (3h.t "inundação" - duração de julho a novembro), peret (pr.t "semeadura" - novembro a março) e shemu (šmw "colheita" - março a julho).
} 
o ano egípcio eram denominados pelos gregos de "Epagômenos", e eram dias festivos, ligados ao mito de Geb e Nut, ou seja, ao par de deuses provenientes do segundo ato de criação divina, de acordo com a escola de Heliópolis. Como o ano solar apresenta uma duração de cerca de 365 dias e 1/4 de dia de cada ano, o que nos faz compensar essa diferença com um dia a mais no ano a cada ciclo de quatro, os egípcios ajustavam o seu calendário a cada mil quatrocentos e sessenta anos, quando o primeiro dia do "ano civil" voltava a coincidir com o do ano astronômico.

Contudo, para além do conhecimento da periodicidade que rege os ciclos naturais, a construção cultural do tempo para os egípcios era costurada pelos ciclos terrenos de ascensão e morte de um faraó reinante, visto que o rei, "Hórus vivo", era o representante máximo da ordem divina na terra, doador de Maat à sociedade e à natureza. Cada reinado formava uma espécie de nova era que se iniciava com a entronização de um dado faraó, e se findava com a sua morte. A cada nova ascensão régia, um ciclo era reiniciado, simbolizando, portanto, a recriação cíclica do cosmos. Assim, dizia-se: sétimo ano do reinado do faraó Mer-en-Ptah. Quando um faraó morria, o ciclo era concluído, e voltava-se ao ano um a partir do qual o tempo era contado novamente.

Como já amplamente discutido, a construção da "História do Antigo Egito" pela historiografia moderna, principalmente a partir dos oitocentos, foi baseada em critérios de organização e atribuição de sentido consoante a cosmovisão partilhada pelo universo intelectual daquela época. Num esforço de sistematização do conhecimento, a história faraônica foi dividida em três reinos, além de ser tomada de empréstimo dos anais de Manethon a divisão clássica em trinta e uma Dinastias.

Manethon, segundo os poucos dados de que dispomos, foi um sacerdote egípcio nascido em Sebenitos, no Delta, que na primeira metade do terceiro século antes de Cristo escreveu em grego uma história do Egito para o Rei Ptolomeu II Filadelfo, denominada Aegyptiaca. Conhecemos tal obra de maneira indireta e fragmentada, pois foi citada por autores antigos como o judeu Josefo (século I); e pelos cristãos Júlio, o 
africano (cerca de 218 a.C); Eusébio de Cesareia (cerca de 320 d.C); e Jorge, o Sincelo (no ano de 800 d.C.).

O legado da divisão em dinastias deixado aos egiptólogos modernos, (vale ressaltar que, as trinta e uma dinastias eram precedidas pelo reinado terreno de deuses e semideuses, e a contagem das dinastias iniciava-se definitivamente com o primeiro faraó a unificar as duas terras, Menés, finalizando-se com Nectanebo II $^{73}$ ), Manethon também especificou a duração dos reinados, repetiu anedotas relativas à vida dos monarcas e relacionou nomes. A narrativa produzida pelo sacerdote da era ptolomaica é, portanto, a referência cronológica mais antiga da sucessão régia egípcia.

Além da identificação do nome do faraó, a maioria delas especifica a data de sua morte, a coroação de seu sucessor, as festas religiosas mais significativas, a construção de palácios e templos, a fabricação de estátuas, a altura atingida pelas cheias do Nilo, as viagens marítimas, as expedições comerciais ou militares, as observações astronômicas. Reiterando o que já foi anteriormente aludido, tais descrições factuais de marcos considerados relevantes para os antigos egípcios não podem ser encaradas como a produção do gênero narrativo História, já que não existe um telos, ou seja, um sentido próprio no transcorrer dos acontecimentos terrenos que justificasse as dinâmicas vivenciadas em tal sociedade. O tempo sempre seguiu um ritmo cíclico e eterno.

Justamente por ser concebido dessa forma, os domínios cronológicos da antiga Kemet ainda são parcialmente obscuros para historiadores e egiptólogos da atualidade. Além, é claro, das referências de Manethon serem fragmentárias, os egípcios construíram a memória da sua realeza de acordo com o que consideravam estar ou não em consonância com a ordem, com a tradição, portanto, inscritas no âmbito de Maat. A Lista de Abydos, por exemplo, não menciona a invasão dos hicsos nem o nome de Akhenaton (e nem dos demais faraós de Amarna) tampouco de Hatshepsut. O que importava para os protagonistas de tal experiência social era a inserção do faraó em

\footnotetext{
${ }^{73}$ De acordo com a historiografia contemporânea, esses reinados se situariam aproximadamente em: Menés (cerca de 3.100 a.C.) e Nectanebo II (360 - 343 a.C.). Referência cronológica extraída de: SHAW, lan \& Paul Nicholson. British Museum Dictionary of Ancient Egypt. London: British Museum Press, 1997.
} 
uma dada ordem cósmica, e não o rigor metodológico moderno que vê a necessidade do estabelecimento de uma linearidade causal que justificaria no movimento histórico o próprio sentido da mudança.

Assim, não podemos fazer uma leitura da sociedade egípcia a partir da preconcepção de que, sendo o seu horizonte a eternidade, o homem egípcio desprezaria a vida mundana. Pelo contrário, só há existência porque há materialização da essência da criação, por isso o Egito, mantido em harmonia por Maat, é espelho do cosmos, ou seja, a existência só é possível pela deusa/princípio. E essa "história egípcia" ao calar, revela os aspectos culturais mais significativos dessa peculiar experiência social. A construção do tempo histórico, como analisa Assmann, pressupõe "irreversibilidade" e "mudança"; já a construção do tempo egípcia enfatiza a "reversibilidade" - Neḥeh - e a "permanência" - Djet -, princípios opostos e complementares. Os egípcios, se tomarmos o entendimento da história por eles mesmos, viviam "fora da história", em um tempo de existência do eterno reviver, que foi determinado, no momento da criação, por Atum, e é renovado a cada novo ciclo.

O entendimento de que Neheh pode ser compreendida como o transcorrer dos ciclos cósmicos e naturais no interior de um espaço de existência mais alargado Djet, também figura em algumas interpretações de egiptólogos: “Djet está imobilizado. Somente em Neheh o tempo se move ${ }^{74}$ (ASSMANN, 1998, p. 18). A riqueza dos princípios, entretanto, parece estar assentada na dinâmica interativa gerada entre eles e não na busca por diferenciações e/ou delimitações de seus universos qualitativos. Finalizaremos com a imagem da última hora do Livro da Amduat, onde o deus sol restaurado durante as doze horas de sua jornada, viajando em sua "barca de milhões de anos", parte na forma de Kheprer-Rá para o alvorecer que é instaurado pelo deus Shu. Esse deus, mas uma vez emerge das águas do Nun, belissimamente representadas, permitindo que o circuito da existência fosse para todo o sempre mantido.

\footnotetext{
${ }^{74}$ Texto extraído da versão em língua inglesa do original em alemão: "Djet is time at a standstill. Only in Neheh does time move".
} 


\section{ب}

回 [ NEARCO

Revista Eletrônica de
Antiguidade e Medievo
NEARCD: Revista Eletrônica de Antiguidade 2020, Volume XII, Número I - ISSN 1982-8713

Núcleo de Estudas da Antiguidade -NEA

Universidade do Estado do Rio de Janeiro

ISSN 1982-8713

Figura 4. Representação da cena correspondente à 12a hora do Livro da Amduat encontrado nas paredes da tumba do faraó Thutmose III - 18a Dinastia (1479 - 1425 a.C.).

Vale dos Reis (Deir el-Bahari), Luxor, Egito.

Fonte: https://theweaverprophecy.wordpress.com/2014/04/17/the-amduatof-ancient-egypt/

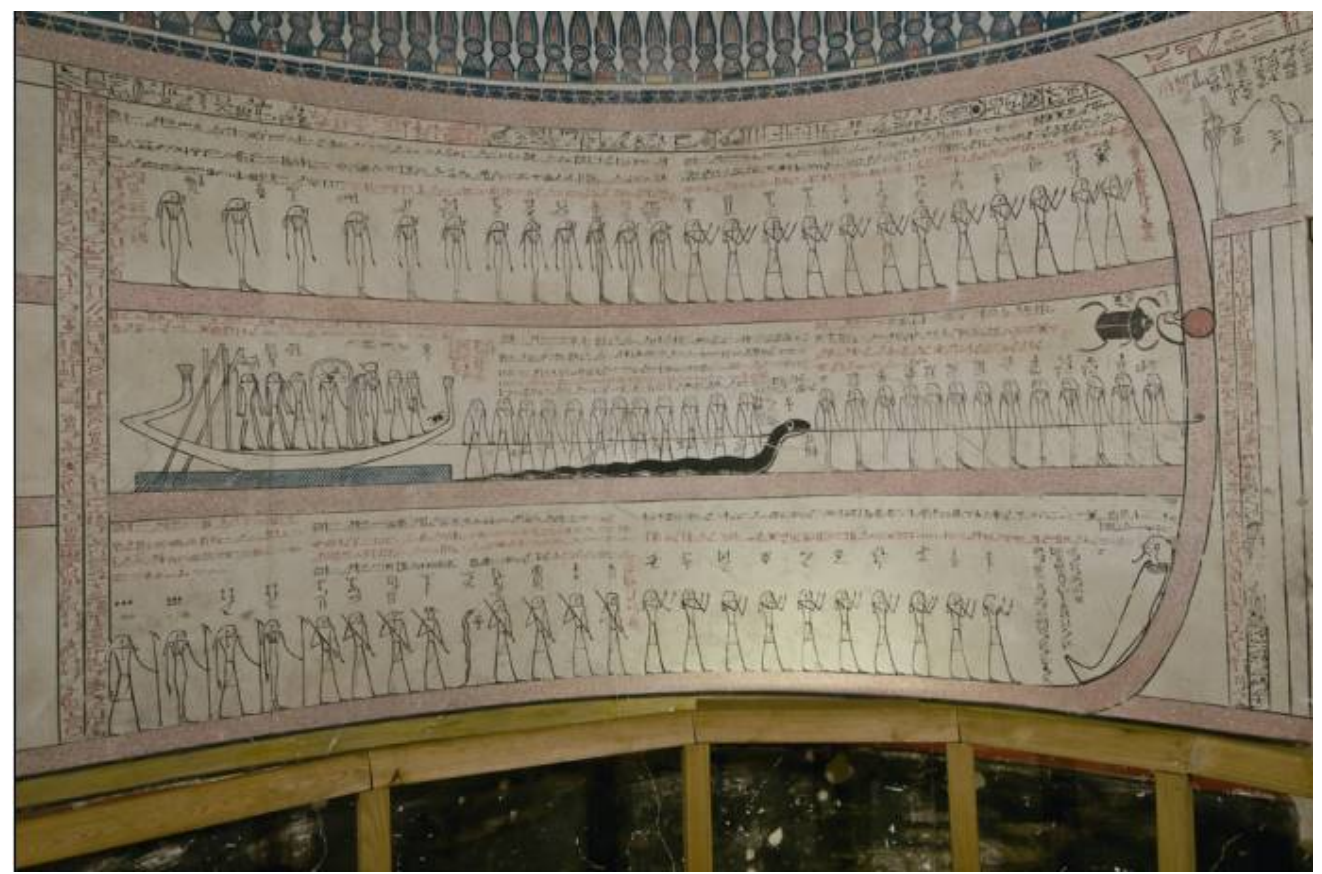

Figura 5. Desenho de uma vinheta (Ícon) da 12a hora do Livro da Amduat encontrado nas paredes da tumba do faraó Thutmose III - 18a Dinastia (1479 - 1425 a.C.).

Vale dos Reis (Deir el-Bahari), Luxor, Egito.

Fonte: desenhado por A.G. Shedid apud HORNUNG,

The Ancient Egyptian Books of the Afterlife.

New York: Cornell University Press, 1999.

Fonte: http://www.sofiatopia.org/maat/hiddenchamber03.h

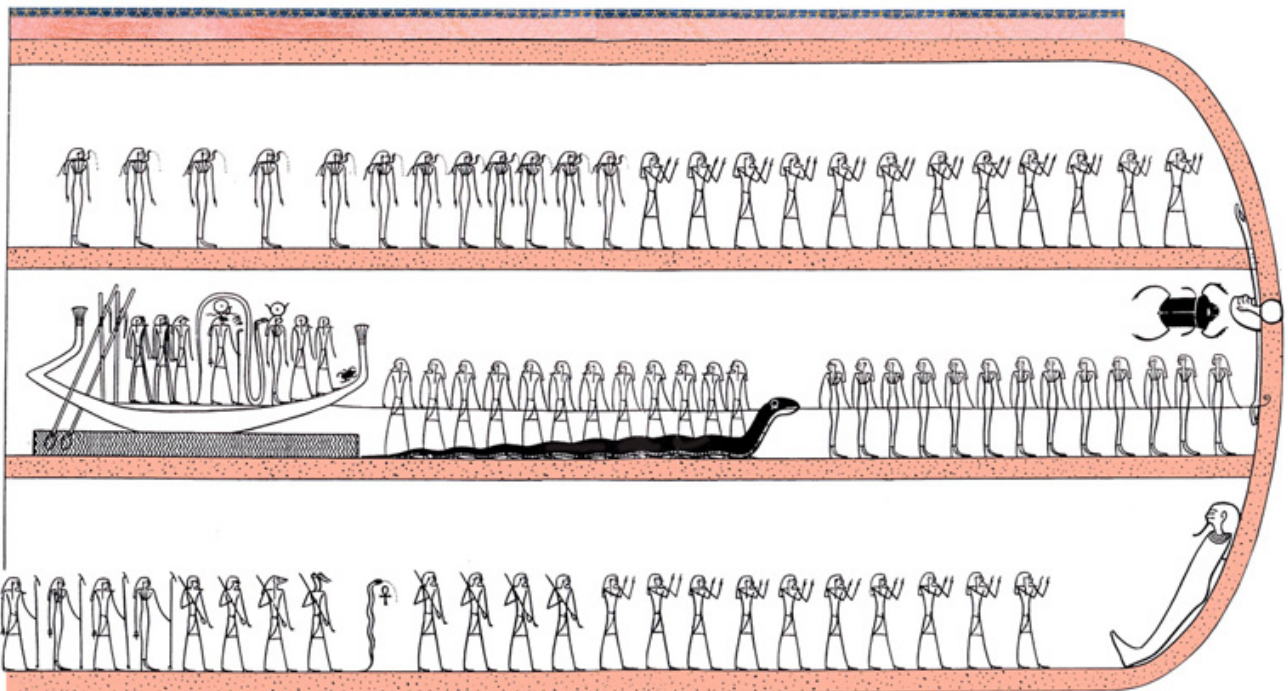




\section{Referências Bibliográficas}

ARAÚJO, Emanuel. Escrito para a eternidade - literatura no Egito faraônico. Brasília: UNB, 2000.

ALLEN, James P. Genesis in Egypt: The philosophy of ancient Egyptian creation accounts. New Haven: Yale University Press, 1998.

ASSMANN, Jan. Religion and cultural memory. Stanford: Stanford University Press, 2006.

ASSMANN, Jan. Maat. L'Egypte pharaonique et l'idee de justice sociale. Paris: Julliard, 1989.

ASSMANN, Jan. The mind of Egypt. History and meaning in the time of the pharaohs. Cambridge: Harvard University Press, 2003. Cambridge: Harvard University Press, 2003.

ASSMANN, Jan. Search for a God in Ancient Egypt. Nova York: Cornell University Press (Ithaca \& London), 2001.

ASSMANN, Jan. "Représentations du temps dans les religions" in PIRENNE-DELFORGE, V., TUNCA, O. (eds.) Actes du Colloque organisé par le Centre d'Histoire des Religions de I'Université de Liège. Liège, Bibliothèque de la Faculté de Philosophie et Lettres de I'Université de Liège, 2003, p. 111-122.

CAMARA, Giselle Marques. Maat: O princípio ordenador do cosmos egípcio. Rio de Janeiro: Revista Atualidade Teológica (PUC-RJ), ano XI, número 26, maio/agosto de 2007.

CARDOSO, Ciro Flamarion. Deuses, múmias e ziggurats. Uma comparação das religiões do Egito e da Mesopotâmia. Porto Alegre: EDIPUCRS, 1999.

CARDOSO, Ciro Flamarion. Hekanakht: pujança passageira do privado no Egito antigo. Niterói, 1993. Tese (Concurso para Professor Titular) - Instituto de Ciências Humanas e Filosofia da Universidade Federal Fluminense, Niterói, 1993.

CARDOSO, Ciro Flamarion. O Egito Antigo. São Paulo: Brasiliense, 1982.

CARDOSO, Ciro Flamarion. Sete olhares sobre a antiguidade. Brasília: Editora da Universidade de Brasília, 1994.

CLARK, R. T. Rundle. Mitos e Símbolos do Antigo Egito. São Paulo: Hemus, 1992.

DAVID, Rosalie. Religion and magic in Ancient Egypt. London: Penguin Books, 2002. 
DUNAND, F. e ZIVIE-COCHE, C. Gods and Men in Egypt: 3000 BCE to 395 CE. New York: Ithaca, Cornell University Press, 2004.

ENGLUND, Gertie e FINNESTAD, Ragnhild Bjerre. The religion of the ancient Egyptians: cognitive structures and popular expressions. Uppsala: Acta Universitatis Upsaliensis, 1989.

FAULKNER, Raymond O. The Ancient Egyptian Pyramid Texts. Oxford: Oxford University Press, 1969.

FORMAN, Werner; Stephen QUIRKE. Hieroglyphs and the Afterlife in Ancient Egypt. Norman: University of Oklahoma Press, 1996.

GUILHOU, N. La Vieillesse des Dieux. Montpellier: Publications de la Recherche Université de Montpellier, 1989.

HORNUNG, Erik. Conceptions of god in Ancient Egypt: the one and the many. New York: Cornell University Press, 1996.

HORNUNG, Erik. Idea into Image. Essays on Ancient Egyptian Thought. New York: Tinken, 1992.

HORNUNG, Erik. The Ancient Egyptian Books of the Afterlife. New York: Cornell University Press, 1999.

HORNUNG, Erik. The Ancient Egyptian Books of the Underworld: the Amduat, the Book of the Gates, the Book of the Caverns, the Litany of Ra. Londres: Intef Institute, 2005.

HORNUNG, Erik. The Egyptian Book of the Gates. Zurique: Living Human Heritage, 2014.

HORNUNG, E.; ABT, T. The Egyptian Amduat, the Book of the Hidden Chamber. Zurich: Living Human Heritage, 2007.

KARENGA, Maulana. Maat: the moral ideal in ancient Egypt - a Study in Classical African Ethics. New York: Routledge, 2004.

LESKO, Barbara S. The Great Goddesses of Egypt. Oklahoma, University of Oklahoma Press, 1999.

PIANKOFF. A. The Shrines of Tut-Ankh-Amon. Nova York: Bollingen Series 40, 1955. 
PIRES, Guilherme Cerejeira Borges. Sentir e narrar o sagrado: em torno da sacralização do (s) espaço (s) aquático (s) e terrestre (s) no Egito Antigo. Dissertação de Mestrado em História - Área de Especialização em Egiptologia - Faculdade de Ciências Sociais e Humanas, Universidade Nova de Lisboa, Lisboa, setembro de 2015.

PIRES, Guilherme Cerejeira Borges. O Tempo e os tempos no Egipto antigo. Uma aproximação metodológica. Lisboa: Ciclo de Estudos de Doutoramento em História Ano Lectivo: 2015-2016, Universidade de Lisboa, 2016.

SALES, José das Candeias. "Calendário" in ARAÚJO, L.M. (dir.). Dicionário do Antigo Egipto. Lisboa, Editorial Caminho, 2001, p.165-167.

SALES, José das Candeias. "A Concepção Antropológica Egípcia: Da Vida no Aquém à Existência no Além". Gaudium Sciendi. Lisboa: Universidade Católica Portuguesa, 2014, p.131-164.

SALES, José das Candeias. "Concepção e Percepção de Tempo e de Temporalidade no Egipto Antigo". In: Política(s) e Cultura(s) no Antigo Egipto. Lisboa, Chiado Editora, 2015.

SHAW, Ian \& Paul Nicholson. British Museum Dictionary of Ancient Egypt. London: British Museum Press, 1997.

SAUNERON, S., YOYOTTE, "La Naissance du Monde Selon L'Égypte Ancienne" in AAVV, La Naissance du Monde, Sources Orientales I. Paris, Ed. Du Seuil, 1959, p. 17-87.

SERVAJEAN, Frédéric. Djet et Neheh. Une histoire du temps égyptien. Montpellier: Université Paul Valéry, 2007.

SERVAJEAN, Frédéric. À propos du temps (neheh) dans quelques textes du Moyen Empire. In: Égypte Nilotique et Méditerranéenne, 1, 2008.

SOUZA, Rogério. O Livro das Origens: a inscrição teológica da pedra de Chabaka. Lisboa: Fundação Calouste Gulbekian, 2011.

TAYLOR, J.H. Death and the afterlife in Ancient Egypt. Londres: The Trustees of the British Museum, 2001.

WILKINSON, Richard $\mathrm{H}$. The complete gods and goddesses of ancient Egypt. London: Thames \& Hudson, 2003.

WYATT, N. Space and Time in the Religious Life of the Near East. Sheffield: Sheffield Academic Press, 2001. 
NEARCD: Revista Eletrônica de Antiguidade 2020, Volume XII, Número I - ISSN 19882-8713

Núcleo de Estudas da Antiguidade -NEA

Universidade do Estada do Rio de Janeiro

ISSN 1982-8713

YOYOTTE, Jean. Les Pèlerinages dans l'Égypte Ancienne. In: Les Pèlerinages, Sources Orientales. Paris, Éd. Du Seuil, 1960.

ZAMACONA, C.G. Space, Time and Abstract Relations in the Coffin Texts. In: Zeitschrift für Ägyptische 137. Leipzig, Universität Leipzig, 2010, p.13-26. 